\title{
Effect of positive airway pressure oscillations on human epithelial cells
}

\author{
Sandra Grau-Bartual ${ }^{1}$, Ahmed M. Al-Jumaily ${ }^{2}$, Maliheh Ghadiri ${ }^{3}$ \\ ${ }^{1,2}$ Institute of Biomedical Technologies, Auckland University of Technology, Auckland, New Zealand \\ ${ }^{3}$ Woolcock Institute of Medical Research, University of Sydney, Sydney, Australia \\ ${ }^{1}$ Corresponding author \\ E-mail: ${ }^{1}$ sandra.graubartual@aut.ac.nz, ${ }^{2}$ ahmed.aljumaily@aut.ac.nz, ${ }^{3}$ maliheh.ghadiri@sydney.edu.au
}

Received 29 April 2019; accepted 10 May 2019

DOI https://doi.org/10.21595/vp.2019.20756

Check for updates

Copyright $(2019$ Sandra Grau-Bartual, et al. This is an open access article distributed under the Creative Commons Attribution License, which permits unrestricted use, distribution, and reproduction in any medium, provided the original work is properly cited.

\begin{abstract}
Lung supportive devices are widely used for respiratory ventilation and therapy to help providing breathing support for patients with various lung diseases including Obstructive Sleep Apnea. These devices deliver continuous air to the patient through a nasal or a facial mask. However, the use of these devices normally results in dryness in the upper airways. Various methods have been developed to improve the continuous positive pressure features using pressure oscillations, which can reduce the patient requirements such as reduction in the titration pressure and humidification requirements. Thus, the objective of this research is to investigate the differences between continuous positive pressure and positive pressure oscillation on the upper airway humidification. Human nasal (RPMI 2650) and bronchial (Calu-3) epithelial cells grown in air-liquid interface on permeable supports are used as a respiratory model. Trans-epithelial electrical resistance is measured before and after each experiment to evaluate the cell layer integrity and permeability.
\end{abstract}

Keywords: CPAP, OSA, pressure oscillations, Calu-3, RPMI 2650, TEER.

\section{Introduction}

Lung supportive devices (LSD) are widely used for respiratory ventilation and therapy to help providing breathing support for patients with various lung diseases including obstructive sleep apnea (OSA). These devices deliver continuous air to the patient through a nasal or a facial mask. However, the use of these devices normally results in dryness, sneezing, rhinorrhea, post-nasal drip, nasal congestion or epistaxis in the upper airways [1].

Various methods have been developed to improve the continuous positive pressure features using pressure oscillations (PO), which can reduce the patient requirements such as reduction in the titration pressure, which is the positive airway pressure needed to keep the airways opened, and humidification requirements. To reduce tissue deformation, some research lines are focused on the possibility that many afferent neural receptors are stimulated by the vibration occurring during snoring [2-4]. Following these scientific advances, an alternative to conventional continuous positive airway pressure (CPAP) treatment has been studied applying superimposed oscillation pressures in order to maintain the airway open, which is as efficient as constant CPAP in the treatment of OSA and is able to reduce titration pressure [2-4]. However, these studies do not investigate the effect of the superimposed oscillation pressures on the respiratory epithelium.

The purpose of this investigation is to analyze and compare the human respiratory epithelium response under conventional CPAP and applying superimposed oscillation pressures. Human bronchial epithelial Calu-3 cells and nasal RPMI 2650 cells grown in air-liquid interface (ALI) on permeable supports are used as in-vitro respiratory models. 


\section{Methods}

\subsection{Cell culture}

RPMI 2650 cells derived from nasal septum carcinoma and Calu-3 cells derived from metastatic lung adenocarcinoma (ATCC, USA) were grown in Minimum Essential Medium and Dulbecco's Modified Eagle's medium/F-12, for each cell line respectively, containing $10 \%(\mathrm{v} / \mathrm{v})$ fetal bovine serum, $1 \%$ (v/v) non-essential amino acid solution, and $2 \mathrm{mM}$ L-glutamine, according to the manufacturer's protocol. Cells were incubated in a humidified atmosphere of $95 \%$ air and $5 \% \mathrm{CO}_{2}$ at $37^{\circ} \mathrm{C}$. The medium was replaced three times a week and cells were passaged at a ratio of $1: 3$. Calu-3 cells were seeded at an initial density of $1.65 \times 10^{5}$ cells/insert on Transwell ${ }^{\circledR}$ polyester inserts, the RPMI 2650 cell inserts were previously coated with $200 \mu \mathrm{L}$ of $1 \mu \mathrm{g} / \mathrm{mL}$ collagen solution in phosphate buffered saline (PBS). After 24 hours, ALI model was created by aspirating the apical medium and the cells were maintained with $0.5 \mathrm{ml}$ of culture medium in the basolateral chamber. The ALI conditions stimulated differentiation of the cell layer and were ready for the experiments after 11 days $[5,6]$.

\subsection{Cell viability}

Cell viability assay after CPAP application was performed using trypan blue exclusion analysis to confirm cells could tolerate the maximum pressure used within the experimental time. Cells grown on transwells were exposed to $20 \mathrm{~cm} \mathrm{H}_{2} \mathrm{O}$ CPAP for 10 minutes. Subsequently, the cells were rinsed with PBS, trypsinised, centrifuged and suspended in $1 \mathrm{ml}$ medium. A $100 \mu \mathrm{l}$ trypan blue $(0.4 \%)$ and $500 \mu \mathrm{l}$ cell solution were then added to a centrifuge tube and mixed thoroughly. The solution was allowed to incubate at room temperature for $5 \mathrm{~min}$. Viable and non-viable cells were counted using a hemocytometer. Cells exposed to $0 \mathrm{~cm} \mathrm{H}_{2} \mathrm{O}$ CPAP (no-pressure applied) were used as control samples.

\subsection{Trans-epithelial electrical resistance}

To assess the effect of the positive airway pressure oscillations, trans-epithelial electrical resistance (TEER) measurements were performed in real-time without cell damage using the electric cell-substrate impedance sensing system (ECIS ${ }^{\circledR}$; Applied BioPhysics, Troy, NY). TEER was measured on the cells grown on transwells using an $8 \mathrm{~W}$ ECIS filter adaptor at $1000 \mathrm{~Hz}$. The ECIS device was placed inside an incubator at $37{ }^{\circ} \mathrm{C}$ with $95 \%$ air and $5 \% \mathrm{CO}_{2}$. Subsequently, $100 \mu \mathrm{l}$ and $800 \mu \mathrm{l}$ of PBS were added to the apical and basolateral chamber, respectively, as electrolyte solution to allow the transmission between the electrodes. Data was recorded every 5 minutes. TEER was measured for one hour before applying the pressure to collect the baseline resistance. Then, apical PBS was aspirated from all inserts, and pressure was applied on the cells, followed by adding $100 \mu \mathrm{l}$ of PBS to the apical chamber and the resistance was measured consequently. Data was normalized by subtracting the resistance values from cell-free inserts and multiplied by the surface area of insert $\left(0.34 \mathrm{~cm}^{2}\right)$ using ECIS software. Resulting values are an indicator of cell layer integrity and permeability.

\section{Experimental setup}

The continuous positive pressure was generated using a CPAP device (FP Healthcare, NZ) connected to an airtight custom-made $600 \mathrm{~cm}^{3}$ cell holder to maintain the desired pressure on the cells during the experiments. To generate the superimposed pressure oscillation, a function generator AFG3120C (Tektronix, SW, USA) was connected to an electrodynamic vibration shaker (The Modal Shop, OH, USA) and a $125.66 \mathrm{~cm}^{3}$ custom-made piston to produce a sinusoidal pressure variation superimposed to the $5,10,15$ and $20 \mathrm{~cm} \mathrm{H}_{2} \mathrm{O}$ CPAP pressures, setup outlined in Fig. 1. According to previous literature findings on human genioglossus stimulation [2-4], a 
signal amplitude of $\pm 1 \mathrm{~cm} \mathrm{H}_{2} \mathrm{O}$ amplitude and three frequencies, 10, 20 and $30 \mathrm{~Hz}$, were selected for the cell experiments.

\section{Results}

Statistical analysis was performed using GraphPad Prism software (GraphPad, San Diego, CA, USA) version 6.07 for windows using two-way analysis of variance (ANOVA), followed by Tukey post hoc analysis for multiple comparisons. Results are presented as mean \pm standard deviation (SD) of three independent experiments $(n=3)$.

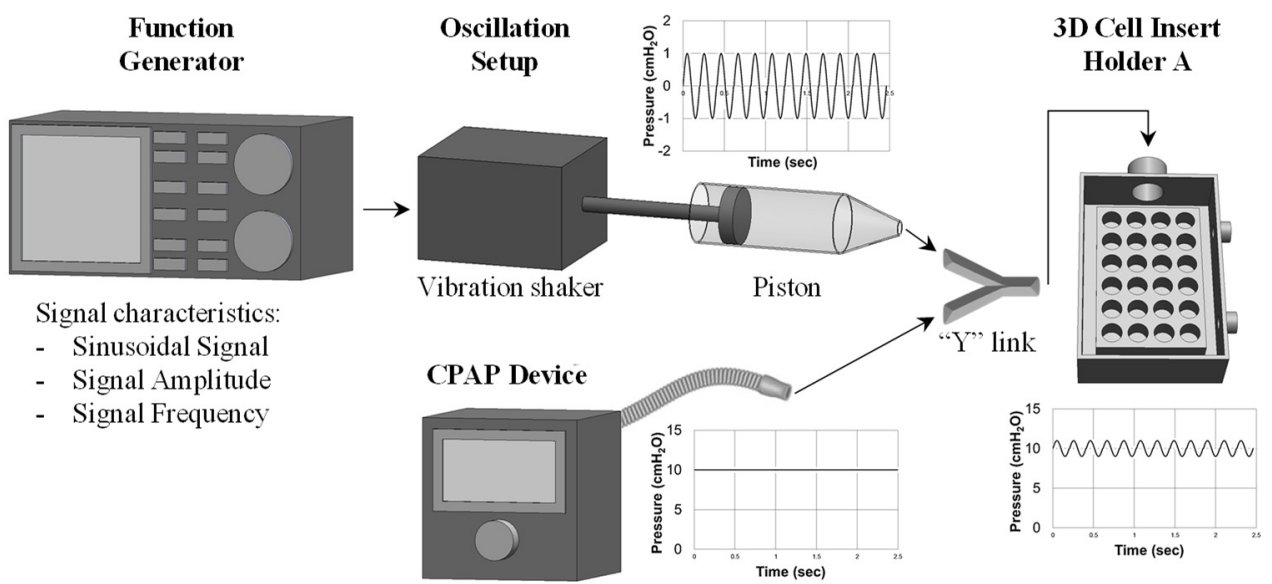

Pressure: $5,15,15$ or $20 \mathrm{cmH}_{2} \mathrm{O}$

Fig. 1. Schematic diagram to describe the process and set up to generate $\pm 1 \mathrm{~cm} \mathrm{H}_{2} \mathrm{O}$ sinusoidal pressure oscillation superimposed to $10 \mathrm{~cm} \mathrm{H}_{2} \mathrm{O}$ continuous pressures on the cell lines. Pressure readings as a function of time were measured with the $2080 \mathrm{P}$ digital manometer

Cell viability assay showed that applying $20 \mathrm{~cm} \mathrm{H}_{2} \mathrm{O}$ CPAP for 10 minutes, minimum experimental time considered to avoid a bacterial contamination risk based on previous literature [4], to both cell lines did not cause significant cell death. The percentage of viable cells after CPAP application was compared to the control (no-pressure applied) in both cell lines (data not shown). Cell viability data indicates that both cell lines could survive the positive pressure application for 10 minutes.
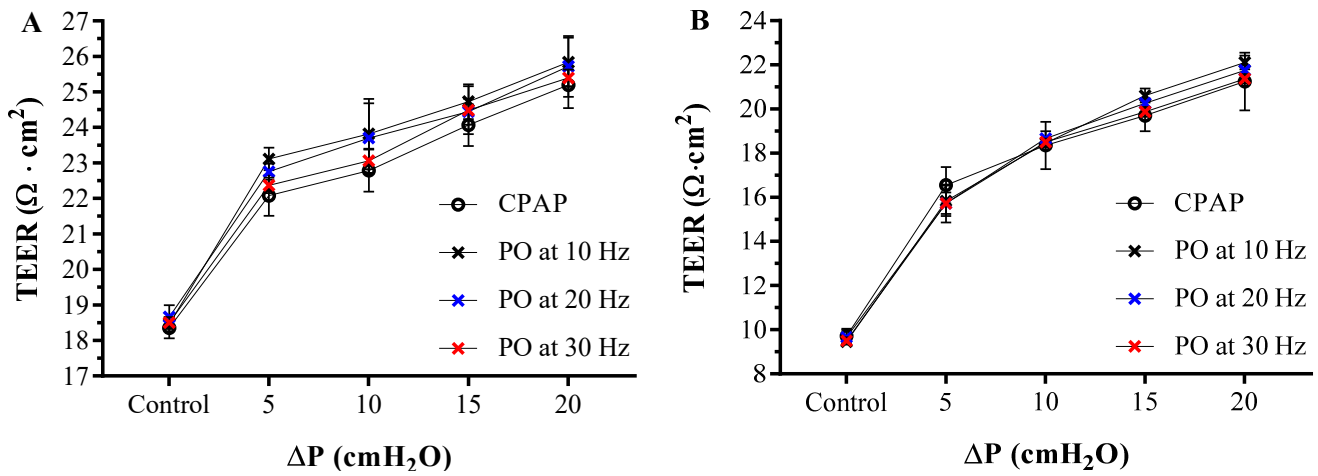

Fig. 2. TEER values measured at control $\left(\Delta P=0 \mathrm{~cm} \mathrm{H}_{2} \mathrm{O}\right)$ and $\Delta P=5,1015$ and $20 \mathrm{~cm} \mathrm{H}_{2} \mathrm{O}$ of CPAP and $\Delta P=5 \pm 1,10 \pm 1,15 \pm 1$ and $20 \pm 1 \mathrm{~cm} \mathrm{H}_{2} \mathrm{O}$ of superimposed $\mathrm{PO}$ at 10,20 and $30 \mathrm{~Hz}$ with the ECIS apparatus at $1000 \mathrm{~Hz}$. A- TEER values for Calu-3 cells. B- TEER values for RPMI 2650 cells

Cell layer integrity and electrical permeability on Calu-3 and RPMI 2650 cell lines after 0 
(control), $5 \pm 1,10 \pm 1,15 \pm 1$ and $20 \pm 1 \mathrm{~cm} \mathrm{H}_{2} \mathrm{O}$ PO at 10,20 and $30 \mathrm{~Hz}$ for 10 minutes measured using the ECIS apparatus at $1000 \mathrm{~Hz}$ of frequency was evaluated and compared with 0 (control), 5, 10, 15 and $20 \mathrm{~cm} \mathrm{H}_{2} \mathrm{O}$ CPAP results. The TEER values obtained are shown in Fig. 2.

The TEER values measured after the superimposed pressure oscillation follow the same trend as the TEER values obtained after CPAP application, and the values increase significantly with $\Delta P$. After any pressure application the electrical current has more resistance to pass through the cell layer resulting in higher TEER values compared to the control. This means that the cell layer is less permeable after pressure application and cell layer integrity remains intact. Otherwise, if the cell layer was damaged, lower TEER values compare to the control were expected.

However, the difference on the TEER values between the superimposed pressure oscillations and the CPAP application is not significant at any frequency in any of the 5, 1015 and $20 \mathrm{~cm} \mathrm{H}_{2} \mathrm{O}$ positive pressure applied. These results indicate that superimposed PO effect of the cell epithelium do not differ from conventional CPAP treatment at any pressure or frequency.

\section{Conclusions}

The purpose of this investigation was to analyze and compare the human respiratory epithelium response under conventional CPAP and applying superimposed oscillation pressures using two in-vitro respiratory models.

Applying pressure on the epithelial cells using CPAP indicates that cells can survive the $20 \mathrm{~cm} \mathrm{H} \mathrm{H}_{2} \mathrm{O}$ pressure for 10 minutes and that the cell layer integrity remains intact. However, TEER measurements showed that the cell layer is less permeable after pressure application, which suggest a possible compression effect also indicated in previous literature [7]. Comparing the conventional CPAP treatment with superimposed PO, it is seen that TEER values measured after the superimposed pressure oscillation follow the same trend as the TEER values obtained after CPAP application, with no significant difference between the superimposed pressure oscillations and the CPAP application at any frequency. These results indicate that superimposed PO effect of the cell epithelium do not differ from conventional CPAP treatment at any pressure or frequency and could be used as an alternative CPAP treatment to reduce titration pressure on OSA patients.

\section{Acknowledgements}

Thanks to the Auckland University of Technology for supporting financially over three years through the Vice Chancellor's Doctoral Scholarship. Also, thanks to Professor Paul Young and Professor Daniela Traini, professors in respiratory science at the University of Sydney, for providing all facilities, valuable suggestions and support.

\section{References}

[1] Malik N. W., Kenyon G. S. Changes in the nasal airway mucosa and in nasal symptoms following continuous positive airway pressure (N-CPAP) for obstructive sleep apnea. Australian Journal of Otolaryngology, Vol. 7, Issue 1, 2004, p. 17-20.

[2] Vanderveken O. M., Oostveen E., Boudewyns A. N., Verbraecken J. A., Van De Heyning P. H., De Backer W. A. Quantification of pharyngeal patency in patients with sleep-disordered breathing. Journal for Oto-Rhino-Laryngology, Head and Neck Surgery, Vol. 67, Issue 3, 2015, p. 168-79.

[3] Randerath W. J., Schraeder O., Galetke W., Feldmeyer F., Ruhle K. H. Autoadjusting CPAP therapy based on impedance efficacy, compliance and acceptance. American Journal of Respiratory and Critical Care Medicine, Vol. 163, 2001, p. 652-657.

[4] Ficker J. H., Clarenbach C. F., Neukirchner C., Fuchs F. S., Wiest G. H., Schahin S., Harsch I. A., Hahn E. G. Auto-CPAP therapy based on the forced oscillation technique. Biomedical Engineering / Biomedizinische Technik, Vol. 48, 2003, p. 68-72.

[5] Haghi M., Young P. M., Traini D., Jaiswal R., Gong J., Bebawy M. Time- and passage-dependent characteristics of a Calu-3 respiratory epithelial cell model. Drug Development and Industrial Pharmacy, Vol. 36, Issue 10, 2010, p. 1207-1214. 
[6] Pozzoli M., Ong H. X., Morgan L., Sukkar M., Traini D., Young P. M., Sonvico F. Application of RPMI 2650 nasal cell model to a 3D printed apparatus for the testing of drug deposition and permeation of nasal products. European Journal of Pharmaceutics and Biopharmaceutics, Vol. 107, 2016, p. 223-233.

[7] Grau Bartual S., Al Jumaily A.-M., Young P. M., Traini D., Ghadiri M. Effect of positive airway pressure on human nasal and bronchial epithelial cells. Respiratory Drug Delivery, Vol. 2, 2018, p. 317-320. 